Original Article - Clinical Science

\title{
Longitudinal changes in global cataract surgery rate inequality and associations with socioeconomic indices
}

William Yan MBBS, ${ }^{1,3,4}$ Wei Wang MD PhD, ${ }^{2}$ Peter van Wijngaarden PhD FRANZCO, ${ }^{1,4}$ Andreas Mueller $\mathrm{PhD}^{1,3,4}$ and Mingguang He PhD FRANZCO ${ }^{1-4}$

${ }^{1}$ Centre for Eye Research Australia, The Royal Victorian Eye and Ear Hospital, East Melbourne, Victoria, Australia 3002

${ }^{2}$ State Key Laboratory of Ophthalmology, Zhongshan Ophthalmic Center, Sun YatSen University, Guangzhou, China 510085

${ }^{3}$ World Health Organization Collaborating Center for Prevention of Blindness, Centre for Eye Research Australia (CERA), University of Melbourne, East Melbourne, Victoria, Australia

${ }^{4}$ Ophthalmology, Department of Surgery, University of Melbourne, Parkville, Victoria, Australia

Correspondence: Dr William Yan, Centre for Eye Research Australia, The University of Melbourne, Royal Victorian Eye and Ear Hospital, East Melbourne, Victoria, Australia 3002

Email: William.wl.yan@gmail.com

Short running title: Changes in global cataract surgery rate inequality

Received 14 September 2018; accepted 22 October 2018

Funding sources / Financial disclosure: None

Conflict of interest: None

This is the author manuscript accepted for publication and has undergone full peer review but has not been through the copyediting, typesetting, pagination and proofreading process, which may lead to differences between this version and the Version of Record. Please cite this article as doi: 10.1111/ceo.13430

This article is protected by copyright. All rights reserved. 


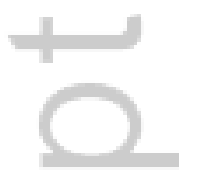




\section{ABSTRACT}

Importance: Cataract is the leading cause of blindness and the second leading cause of vision impairment. The majority of people with vision impairment reside in low-resource settings with limited access to cataract surgery and services.

Background: Cataract surgery rate (CSR) is a proxy measure for eye care service delivery and estimating the burden of cataract disease. This research aims to evaluate the longitudinal changes of CSR inequality globally and by income groups.

Design: Systematic Review

Participants: Studies published from January 2000 to December 2015 were considered for inclusion into the review.

Methods: CSR data were retrieved from a systematic review of published literature (OVID Medline, Embase, Pubmed, ISI, Web of Science), unpublished reports and data repositories.

Main Outcome Measures: Inequality of CSR was measured on a global scale and between countries grouped by income levels using the Gini coefficient and Concentration index, with respect to the Human Development Index (HDI).

Results: Overall, correlations between HDI and GDP per capita versus CSRs were observed with $R^{2}$ values of $49.2 \%(\beta=5.01, P<0.001)$ and $38.9 \%(\beta=0.56, P<$ 0.001 ) respectively. Analysis of longitudinal CSR data using Generalised Estimation Equation (GEE) models revealed strong associations between CSR and HDI $(P<$ $0.001)$, GDP $(P<0.001)$ and the proportion of people aged $\geq 50(P=0.001)$. Overall, the trend of inequality in worldwide CSR remained relatively stable.

Conclusions and Relevance: Inequalities in cataract service provision were found between countries grouped by income and associated with socioeconomic indicators.

Keywords: cataract surgery rate; socioeconomics; health inequality; 


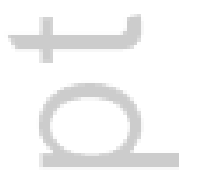




\section{INTRODUCTION}

The World Health Organisation (WHO) estimates that over $90 \%$ of the world's vision impaired reside in low-income settings, and that over $80 \%$ of global blindness is preventable with early detection or treatment.[1] Cataract is identified as the leading cause of global blindness, accounting for approximately $51 \%$ of cases, and is the second-leading cause of moderate to severe vision impairment (MSVI) following uncorrected refractive error.[2] In 2013, the World Health Assembly endorsed the Global Action Plan (Universal Eye Health: A global action plan 2014-2019) which aimed to reduce the worldwide prevalence of preventable blindness by $25 \%$ before the year 2019.[3] As the ongoing costs of VI are substantial to both individuals and at a societal level, blindness prevention programs may effectively break the cycle of poverty associated with vision impairment, particularly within the socio-economic constraints of low-income regions. The Global Action Plan (GAP) defines cataract as a condition of priority given the restorative nature of treatment and generally good visual outcomes of surgery.[4] Although cataract surgery is considered one of the most cost-effective medical interventions by cost-utility when valued using qualityadjusted life years (QALYS), unoperated cataract remains a leading cause of MSVI and blindness in low- and middle-income countries.[5-10]

Country and regional CSR data documentation is necessary to monitor the provision of cataract services as it is considered a proxy measure of cataract disease burden and access to cataract surgery services. Previous research has demonstrated that CSR is closely associated with levels of socioeconomic development [11, 12], which is commonly expressed in economic value as a country's gross domestic product (GDP), gross national income (GNI) or in social value as the human development index (HDI). The CSR variation between countries and within countries and may reflect differences in underlying regional health service delivery and efficiency. Traditional measures of statistical dispersion such as the Gini coefficient and the 
Concentration Index (CI) have been used to study income and wealth distributions within countries, but these can also be used to assess distributions of healthcare access. The Gini index is a univariate measure of concentration while the concentration index allows one to measure the concentration of a single variable such as CSR with respect to another, such as socioeconomic development (i.e. HDI). [13] [14] The Gini coefficient can be calculated from statistical representations of income and wealth distributions and ranges from 0 (absolute equality) to 1 (absolute inequality).[15] The $\mathrm{CI}$ is calculated from the distribution of a variable of interest assessed against an indicator of living standards, such as the Human Development Index (HDI), reflecting the socioeconomic dimension of health inequalities.

Although the association between CSR and socioeconomic factors has been demonstrated previously, this is, to the best of our knowledge, the first study of the relative longitudinal changes of CSR inequality and its association with socioeconomic development. Understanding the absolute changes in CSR equality and change relative to GDP progression may highlight contexts where investment in blindness prevention programs is inadequate relative to global norms. The present research aims to evaluate longitudinal changes of CSR inequality globally and in high-, low- and middle-income groups, its association with socioeconomic development.

\section{METHODS}

\subsection{Data sources}

Country CSR data were obtained by searching electronic databases of published literature (OVID Medline, Pubmed, Embase, ISI, Web of Science, and Cochrane Reviews) using standardized search terms (Appendix 1), as well as through unpublished reports in the grey literature. Eligibility of CSR data inclusion was 
restricted to reports of age-related cataract among adults using any cataract surgery method, including extracapsular cataract extraction (ECCE), small incision cataract surgery (SICS), and phacoemulsification with implantation of an intraocular lens. Reference lists of reviews and retrieved studies were also screened for suitable studies. Studies published from January 2000 to December 2015 were considered for inclusion into the review. Inclusion criteria for published studies were as follows: 1) cross-sectional studies, cohort studies, or surveys; 2) studies with a clearly described sampling methodology (random, specified or stratified national or population-based sampling); and 3) response rate of greater than 50\%.[16] All studies meeting the inclusion criteria were included for meta-analysis, and no studies were excluded on basis of language. Case series studies of hospital and clinic data were excluded from analysis. Data from unpublished grey literature were sourced from the OpenGrey database (http://www.opengrey.eu/) and non-government organisation (NGOs) websites including the RAAB repositories (http://www.raabdata.info/), Rapid Assessment of Cataract Surgical Services (RACSS) data, Global Burden of Disease (GBD) surveys (http://www.healthdata.org/gbd), Global Health Data Exchange repositories (http://ghdx.healthdata.org/), WHO database (http://www.who.int/), WHO Library Information System (WHOLIS), IAPB database (http://www.iapb.org/home), as well as national or district CSR reporting registries (Sweden, Malaysia, European Union) and National Ministry of Health websites available in the public domain. The Google search engine (http://www.google.com) was used to supplement the national CSRs of countries when information from CSR reports were incomplete from the aforementioned sources. Relevant GDP data per capita (GDP/P, purchasing power parity method) were obtained from the World Bank (http://data.worldbank.org/) and standardized using 2011 International Dollars. HDI data were collected from the United Nations Development Program (UNDP) Human Development Reports (http://hdr.undp.org/en/data). Institutional review board (IRB) approval was not 
required for this study as all data were extracted from databases and publications available in the public domain and no individual patient data were collected. A total of 110 peer-reviewed publications were reviewed in full after titles and abstracts were screened. Of the publications reviewed in full, 36 were included in the final analysis. Main reasons for exclusion were study type (prevalence, incidence, risk factors, reviews) or if they were studies from previous publications with the same population cohort. Additional supplementary data were available from 20 NGO government reports and the aforementioned online registries.

\subsection{Data extraction}

Data extraction was performed using a standardized data extraction form including fields of region and country in which the study was conducted, year of publication, year of data collection, age, number of people examined and CSRs with 95\% confidence intervals (CI). Countries were assigned to high, and low- to middleincome groups based on GNI/P data, where a high-income country was classified as GNI/P greater than $\$ 12,736$ USD, while low and moderate-income countries were classified with a GNI/P equal or as less than $\$ 12,736$ USD.[17]

National CSRs were calculated with a numerator of total surgeries performed in a particular year by each country. The CSR data for each country was cross-verified where multiple sources were available including NGOs reports, peer-reviewed papers and government reports. CSR values were averaged between sources where more than one source was available for a country in a given year. Where only the regional and provincial CSRs of a country were reported, the national CSR for the country was calculated by the sum of cataract surgeries performed across regions, and dividing it by the total population contained within the regions and provinces.

\section{3 variables}


GDP expressed per capita is the most frequently reported national indicator of economic development, which is calculated by the total value of domestic goods and services produced divided by the total population. Cataract surgery rate (CSR) is a proxy measure for eye care service delivery and disease burden, and is expressed as numbers of cataract surgeries performed per million population. The HDI is a commonly used indicator of socioeconomic development calculated using metrics across three domains: health (life expectancy at birth), education (mean years of schooling, expected years of schooling) and income (gross national income per capita), expressed as a value between 0.00 and 1.00 with 1.00 reflecting the highest level of development. In the present study HDI values were separated into predetermined quartiles to analyse effect on inequality of distribution: low (0.3260.529); medium (0.544-0.681); high (0.696-0.786); and very high (0.792-0.940). The Gini coefficient is a commonly used measure of inequality in frequency distributions of variables such as income expressed as a value between 0.00 and 1.00 , with 1.00 representing the maximum possible inequality in a significantly skewed distribution. The Concentration index (CI) is a calculation of the inequality of a health variable attributable to socioeconomic factors, and has previously been used in health economic analyses to evaluate whether the socioeconomic contributions to health inequalities vary over time or by geography.[18, 19] Inequality was also analysed in groups according to income using the World Bank Atlas method, after adjusting for the difference between the rate of inflation in the country and that in a number of developed countries using a weighted average of GDP deflators.

\subsection{Statistical analysis}

Statistical analysis was performed between October 2017 and January 2018. Scatterplots representing the associations between socioeconomic indicators and the GDP were generated using GraphPad Prism software, version 5.0 (GraphPad 
Software Inc). A mixed-effects linear model was used to examine the longitudinal changes in CSR and GDP over the study period. Several socioeconomic indices were used to assess the degree of inequality in the provision of cataract surgery, including the Gini coefficient, CI, Thiel Index and Atkinson Index. Although these indices are traditionally used to assess income inequity, their use in assessing the distribution of healthcare resources has also been described elsewhere.[20, 21] In brief, both the Gini index and Atkinson index value ranges from 0 to 1 , with 0 representing a wholly even distribution and 1 representing a wholly uneven distribution. The Thiel Index ranges from 0 to infinity with 0 implying equal distribution and higher values implying greater inequality magnitudes. For this analysis, the sensitivity parameter ( $\varepsilon$ ) was set at 0.5. [22] The corresponding GDP/P data for each year in the period of analysis for each country were used for statistical analysis using the Stata 15 Software Package (StataCorp, College Station Texas, USA). Data from the countries with representative CSR data were used to develop a regression analysis and scatter plots. Regression curve estimation procedures were used to assess the association between CSR and GDP/P (linear, power, quadratic, exponential selected) with $\mathrm{R}^{2}$ statistic used to determine the statistical fit of the model. The effect of HDI on CSR rates was investigated by linear regression analysis. The Gini coefficient was calculated using the Stata 15 INEQERR module and the concentration index by the Stata 15 CONCINDC module. $[23,24]$ A P-value of less than 0.05 was considered statistically significant.

\section{RESULTS}

The distribution of global CSR using the latest global estimate data was mapped in Figure 1. Overall, a strong correlation between HDI and GDP per capita levels and CSRs were observed with $R^{2}$ values of $49.2 \%(\beta=5.01, P<0.001)$ and $38.9 \%$ $(\beta=0.56, P<0.001)$ respectively. Table 1 summarises the longitudinal CSR date 
using General Estimation Equation (GEE) modelling to provide population-averaged estimates of CSR data.[25] Over the study period, most countries experienced an increase in CSR, with the greatest increases observed in Argentina and Iran. Analysis of longitudinal CSR data using GEE models found strong associations between CSR trends and HDI $(P<0.001)$, GDP per capita $(P<0.001)$ and the proportion of people aged 50 and older $(P=0.001)$. The trend in CSR in the longitudinal analysis was not associated with age-standardized prevalence of cataract $(P=0.059, P=$ $0.008)$, density of population $(P=0.403, P=0.346)$, or urbanization rate $(P=$ $0.319, \mathrm{P}=0.197) \cdot[26]$

Overall, the indices for inequality in worldwide CSR distribution remained relatively stable for the study period between 2005 to 2014, with a small increase noted (Table 2). With respect to worldwide CSR distribution, the Gini coefficient remained relatively unchanged between 2006 and 2014 (range 0.484 to 0.487). For the highincome and low- and middle-income country groups, the measure of inequality increased from 0.369 to 0.413 , and 0.395 to 0.429 between 2006 to 2014 . When the CI was analysed with respect to HDI using worldwide CSR distribution, inequality was observed to decrease from 0.431 to 0.390 for the time period. In country groups by high-income, and low and middle-income, inequality by CI increased (range 0.222 to 0.266 , and 0.265 to 0.286 respectively). The CI with respect to GDP using a worldwide CSR distribution showed an overall decrease in inequality from 0.399 to 0.364 , whilst the low and middle-income country group showed an increase in inequality from 0.253 to 0.282 . Concentration index by GDP for high-income countries could not be calculated for the time period due to the lack of available data. Similar trends in inequality were seen for other indices (Figure 2). Both Thiel and Atkinson indices demonstrated a decrease in inequality when analysed by worldwide distribution, but again an increase in inequality was seen when analysed by high-income, and low and middle-income countries, ( 0.195 to 0.273 , and 0.288 to 0.292 respectively). 
Figure 3 demonstrates the change in the logarithm of countries' CSR relative to Australia between 2006 and 2014. Notably, the majority of countries with both low and high proportional CSRs relative to Australia remained so in comparison between the time period. Exceptions to this included Surinante, Argentina and Sri Lanka, which demonstrated an overall increase in CSR relative to Australia, and Kenya, Togo and Sierra Leone, which demonstrated an overall decrease in CSR relative to Australia.

\section{DISCUSSION}

We have evaluated the trend in global cataract service inequality and reported on the trend in CSR associations with socioeconomic indicators such as HDI and GDP across a 10-year period. Cataract surgery rates provide a proxy measure for eye care service delivery and estimating the burden of cataract disease, with cataract blindness accounting for more than $50 \%$ of blindness globally.[1] The longitudinal data demonstrates an association between CSRs and socioeconomic indicators such as HDI and GDP over the study period. Although inequality in the CSR distributions on a global scale remained stagnant over the study duration, the inequality increased when countries were grouped into high-income, or low and middle-income groups. As previously discussed, the Gini coefficient measures CSR inequality in absolute terms of variance independent of other socioeconomic development variables, while CI assesses the CSR inequality with respect to socioeconomic development indices such as HDI and GDP. The observed trend of CSR inequality appears to be robust and is consistent between all four of the study indices.

The estimated worldwide cost burden of vision impairment and blindness is $\$ 3$ trillion and \$27 billion USD respectively, and the majority of people with vision impairment and blindness reside in low and middle-income countries.[27, 28]. HDI 
has been shown to account for more than $70 \%$ of the variance in blindness and MSVI prevalence when analysed at a country level. [29] Consistent with the findings of Ono et al, inequality was greater in the high-income group compared to lowincome groups, reflecting potential differences in drivers for surgery between the groups and the lack of standardised visual impairment indications for surgery. The data suggest that global CSR inequality has largely remained over the study period despite worldwide progression in socioeconomic development as well as overall increasing CSRs.

It is recognised that greater economic wealth is associated with increased resource allocation for cataract services in proportion to overall healthcare expenditure, however this has previously been found to not necessarily follow a needs-based rationale, nor demonstrate equivalence between regions of similar levels of development. [21] This may be due to a set of factors including reduced thresholds of vision impairment as indications for cataract surgery, and the proportion of surgery overall performed in the private sector. In several OECD developed countries, there has been a trend towards reducing thresholds of vision impairment as indications for cataract surgery by insurers and surgeons, owing to improved surgical techniques, technology and functional outcomes. This in turn has also driven increased patient demand. [30-34] In a 2005 Australian population study, it was noted that when the vision impairment threshold for cataract surgery was changed from $6 / 60$ to less than $6 / 12$, the resultant CSR was seen to increase three-fold as a consequence. [30] The appropriate selection and triage of a surgical patient may be equally as important as the absolute number of cataract surgeries performed, especially in the context of healthcare resource limitations. In Sweden between 2002 and 2009 the CSR remained stable at 8000 to 9000 , in the context of a limit placed on the number of annual cataract surgeries in 22 counties and regions due to the competing resource demands of other ophthalmic diseases such as age-related 
macular degeneration. [31]. In spite of this, the overall backlog of unoperated cataract was still observed to decrease, with an overall increase in the proportion of second eye procedures, reflecting an overall increase in cataract service effectiveness.

Comparative analysis of CSR data with other countries across time periods may highlight outliers and prompt studies of the causes of these disparities. Australia was selected as a benchmark in this analysis owing to its consistently high HDI ranking, stable CSRs proportional to overall healthcare expenditures, and the success of cataract surgery programs as evidenced by low overall prevalence of cataract blindness and severe vision impairment.[35-37] Several countries were found to have a significant increase in CSRs, such as Sri Lanka, Suriname. This is reflective of the health policy changes that re-prioritised eye care services, such as investment in phacoemulsification, intensive training, and improvement in the accessibility and affordability of cataract surgery to meet the needs for reducing a substantial backlog of unoperated cataract with VI cases. [38, 39] Conversely, other countries were found to have decreased CSRs such as Kenya, Togo and Sierra Leone. This may be explained by incomplete execution of eye care programs at a national level, poor patient education and outdated practices such as 'couching', and restricted resource allocation to eye care due to competing health issues. This has furthermore resulted in reduced access to eye care providers, from patients being informally charged for surgeons' additional salary compensation. [40, 41]

\subsection{Limitations}

This study provides a novel analysis of the change in global health inequality measured by CSR relative to longitudinal data of HDI and GDP, although there are study limitations that should not be ignored. Firstly, the CSR data collection procedures were not standardised between countries, and as a result the national data for a number of countries were omitted at certain years during the study 
period. This may account for partial reporting or estimation errors of CSR inequality associations. For example, CSR data for 2013 and 2014 were omitted from a majority of NGO reports, while data reported all surgeries performed in the total population irrespective of visual acuity or vision impairment indications for surgery. Possible confounders such as differences in status of healthcare financing or insurance coverage were not included in this study and may have resulted in lower adjusted inequality in both higher-income and low and middle-income country groups. As HDI represents an average value of socioeconomic development for an entire country, significant variations in development levels may exist between regions in a country that are not accounted for using a national average. Finally, the effect of additional variables of interest such as gender and education were not included in the multivariate analysis and may provide greater insight to the driving factors of inequality for countries with similar levels of socioeconomic development by aggregate HDI measures. As the present analysis is an assessment of inequalities using aggregate group data, it is not possible to determine if it is the same socioeconomic groups that are affected most by the CSR inequality. Lastly, the concentration index by GDP for high-income countries could not be calculated for the time period. The lack of available CSR data for high-income countries may be related to the CSR data collection process being primarily from blindness surveys and evaluation of cataract surgery access programs, which has a bias towards lowertier income countries.

Further analysis of changes in the concentration index may account for the health variable heterogeneity that is intrinsic to the data, by deconstructing and reanalysing the composite indices by their individual health variables, as well as the effects of changes in income-related distributions.

\subsection{Conclusion}


This retrospective analysis of CSR trends characterises the change in CSR distribution over time in relation to income-related health inequalities. Although minor increases in inequality are noted between countries when grouped by income status, the overall global inequality was seen to remain relatively stagnant over the study period reflecting that greater emphasis on targeted health policies are required, despite overall increasing CSRs and socioeconomic development. Statistical evaluation of the longitudinal change in CSR variance may reflect inequalities in health service delivery and highlight regional service provision inadequacies. This study provides scope for follow up research investigating not only the extent of absolute inequality in CSR but also in the potential causes of income-related health inequalities observed by the Gini and CIs. The accuracy and collection of CSR data to facilitate this may be improved by establishing national cataract surgery registries that account for differences in visual acuity or vision impairment indications for surgery. 


\section{REFERENCES}

1. Pascolini, D. and S.P. Mariotti, Global estimates of visual impairment: $2010 . \mathrm{Br}$ J Ophthalmol, 2012. 96(5): p. 614-8.

2. WHO, Global data on visual impairments 2010 (WHO/NMH/PBD/12.01). Geneva: WHO, 2012. http://www.who.int/blindness/GLOBALDATAFINALforweb.pdf, 2012.

3. WHO, Universal Eye Health: A Global Action Plan 2014-2019. Available at: http://www.who.int/blindness/actionplan/en/. 2013.

4. Liu, Y.C., et al., Cataracts. Lancet, 2017. 390(10094): p. 600-612.

5. Jonas, J.B., et al., Prevalence and causes of vision loss in Central and South Asia: 1990-2010. Br J Ophthalmol, 2014. 98(5): p. 592-8.

6. Wong, T.Y., et al., Prevalence and causes of vision loss in East Asia: 19902010. Br J Ophthalmol, 2014. 98(5): p. 599-604.

7. Leasher, J.L., et al., Prevalence and causes of vision loss in Latin America and the Caribbean: 1990-2010. Br J Ophthalmol, 2014. 98(5): p. 619-28.

8. Keeffe, J., et al., Prevalence and causes of vision loss in Southeast Asia and Oceania: 1990-2010. Br J Ophthalmol, 2014. 98(5): p. 586-91.

9. Naidoo, K., et al., Prevalence and causes of vision loss in sub-Saharan Africa: 1990-2010. Br J Ophthalmol, 2014. 98(5): p. 612-8.

10. Lansingh, V.C., M.J. Carter, and M. Martens, Global cost-effectiveness of cataract surgery. Ophthalmology, 2007. 114(9): p. 1670-8.

11. Wang, W., et al., Cataract Surgical Rate and Socioeconomics: A Global Study. Investigative Ophthalmology \& Visual Science, 2017. 57(14): p. 5872-5881.

12. Wang, W., et al., A Global View on Output and Outcomes of Cataract Surgery With National Indices of Socioeconomic Development. Investigative Ophthalmology \& Visual Science, 2017. 58(9): p. 3669-3676. 
13. Costa-Font, J. and C. Hernandez-Quevedo, Measuring inequalities in health: what do we know? What do we need to know? Health Policy, 2012. 106(2): p. 195-206.

14. Siegel, M. and P. Allanson, Longitudinal analysis of income-related health inequalities: methods, challenges and applications. Expert Review of Pharmacoeconomics \& Outcomes Research, 2016. 16(1): p. 41-49.

15. Jin, J., et al., Equality of Medical Health Resource Allocation in China Based on the Gini Coefficient Method. Iranian Journal of Public Health, 2015. 44(4): p. 445-457.

16. Richardson, J.T., Instruments for obtaining student feedback: A review of the literature. Assessment \& evaluation in higher education, 2005. 30(4): p. 387415.

17. Bank, T.W. World Bank Atlas Method. 2015; Available from: https://blogs.worldbank.org/opendata/new-country-classifications.

18. O'Donnell, O., et al., conindex: Estimation of concentration indices. The Stata journal, 2016. 16(1): p. 112-138.

19. Erreygers, G. and T. Van Ourti, Measuring socioeconomic inequality in health, health care and health financing by means of rank-dependent indices: $A$ recipe for good practice. Journal of health economics, 2011. 30(4): p. 685694.

20. De Maio, F.G., Income inequality measures. Journal of Epidemiology and Community Health, 2007. 61(10): p. 849-852.

21. Ono, K., Y. Hiratsuka, and A. Murakami, Global Inequality in Eye Health: Country-Level Analysis From the Global Burden of Disease Study. American Journal of Public Health, 2010. 100(9): p. 1784-1788.

22. Erreygers, G., P. Clarke, and T. Van Ourti, "Mirror, mirror, on the wall, who in this land is fairest of all?" - Distributional sensitivity in the measurement of 
socioeconomic inequality of health. Journal of Health Economics, 2012. 31(1): p. 257-270.

23. Jolliffe Dean, K.B., Bootstrap standard errors for indices of inequality: INEQERR. Global Poverty Measurement, 2000.

24. Zhuo, C., CONCINDC: Stata module to calculate concentration index with both individual and grouped data. Statistical Software Components, 2007.

S456802: p. Boston College Department of Economics, Revised 30 Jul 2008.

25. Wedderburn, R.W.M., Quasi-Likelihood Functions, Generalized Linear Models, and the Gauss-Newton Method. Biometrika, 1974. 61(3): p. 439-447.

26. Global, regional, and national incidence, prevalence, and years lived with disability for 310 diseases and injuries, 1990-2015: a systematic analysis for the Global Burden of Disease Study 2015. Lancet, 2016. 388(10053): p. 1545-1602.

27. Gordois, A., et al., An estimation of the worldwide economic and health burden of visual impairment. Glob Public Health, 2012. 7(5): p. 465-81.

28. Frick, K.D. and A. Foster, The magnitude and cost of global blindness: an increasing problem that can be alleviated. Am J Ophthalmol, 2003. 135(4): p. 471-6.

29. Wang, W., et al., Association of socioeconomics with prevalence of visual impairment and blindness. JAMA Ophthalmology, 2017. 135(12): p. 12951302.

30. Taylor, H.R., H.V. Vu, and J.E. Keeffe, Visual acuity thresholds for cataract surgery and the changing australian population. Archives of Ophthalmology, 2006. 124(12): p. 1750-1753.

31. Behndig, A., et al., One million cataract surgeries: Swedish National Cataract Register 1992-2009. J Cataract Refract Surg, 2011. 37(8): p. 1539-45.

32. Gollogly, H.E., et al., Increasing incidence of cataract surgery: populationbased study. J Cataract Refract Surg, 2013. 39(9): p. 1383-9. 
33. Kessel L, H.B., Boberg-Ans G, Henning V, Time Trends in Indication for Cataract Surgery J Clinic Experiment Ophthalmol 2011. 2:174. doi:

\subsection{2/2155-9570.1000174.}

34. Keenan, T., et al., Time trends and geographical variation in cataract surgery rates in England: study of surgical workload. The British Journal of Ophthalmology, 2007. 91(7): p. 901-904.

35. Foreman, J., et al., Cataract surgery coverage rates for Indigenous and nonIndigenous Australians: the National Eye Health Survey. Med J Aust, 2017. 207(6): p. 256-261.

36. Keel, S., et al., Population-based assessment of visual acuity outcomes following cataract surgery in Australia: the National Eye Health Survey. British Journal of Ophthalmology, 2018.

37. Tan, A.G., et al., Comparison of age-specific cataract prevalence in two population-based surveys 6 years apart. BMC Ophthalmol, 2006. 6: p. 17.

38. Pawiroredjo, J.C., et al., The cataract situation in Suriname: an effective intervention programme to increase the cataract surgical rate in a developing country. Br J Ophthalmol, 2017. 101(2): p. 89-93.

39. IAPB, NATIONAL PROGRAMME FOR PREVENTION OF

BLINDNESS SRI LANKA - Comprehensive Eye Plan 2013-2017, V. 2020, Editor. 2013.

40. Potter, A.L., Vandy, M., Smart, N. Blanchet, K.I, Eye Health Systems Assessment (EHSA): Sierra Leone Country Report. Ministry of Health and Sanitation, International Centre for Eye Health, Sightsavers., 2013.

41. Signes-Soler, I., et al., Cataract surgery in West Africa: is couching still a choice? Acta Ophthalmol, 2012. 90(6): p. e488-9. 


\section{TABLES}

Table 1: General estimation equation (GEE) models for CSR and related factors in longitudinal analysis

\begin{tabular}{|c|c|c|c|c|}
\hline Variable & $\beta(95 \% C I)$ & P-value & $\beta(95 \% \mathrm{CI})$ & P-value \\
\hline Human development index & 9929.54 (7728.39 to 12130.69$)$ & $<0.001$ & - & \\
\hline GDP per capita (log scale) & - & & $1069.79(762.59$ to 1376.98$)$ & $<0.001$ \\
\hline Age-standardized prevalence of cataract & $-39531.83(-80533.23$ to 1469.56$)$ & 0.059 & $-54674.88(-95069.08$ to -14280.68$)$ & 0.008 \\
\hline Urbanization rate & $-7.56(-22.43$ to 7.31$)$ & 0.319 & $-10.41(-26.21$ to 5.39$)$ & 0.197 \\
\hline Proportion of people aged 50 and older & $3052.13(-766.57$ to 6870.82$)$ & 0.117 & $6350.13(2715.30$ to 9984.97$)$ & 0.001 \\
\hline
\end{tabular}

Table 2: Inequality of CSR by economic status

\begin{tabular}{|c|c|c|c|c|c|c|}
\hline \multirow{2}{*}{ Inequality measures } & \multicolumn{2}{|c|}{ Worldwide } & \multicolumn{2}{|c|}{ High-income countries } & \multicolumn{2}{|c|}{ Low and middle-income countries } \\
\hline & 2006 & 2014 & 2006 & 2014 & 2006 & 2014 \\
\hline Gini coefficient & 0.484 & 0.487 & 0.369 & 0.413 & 0.395 & 0.429 \\
\hline Concentration index based on HDI & 0.431 & 0.390 & 0.222 & 0.266 & 0.265 & 0.286 \\
\hline
\end{tabular}

This article is protected by copyright. All rights reserved. 


\section{FIGURES}

Figure 1: Distribution map of global CSR using most recent global estimate data

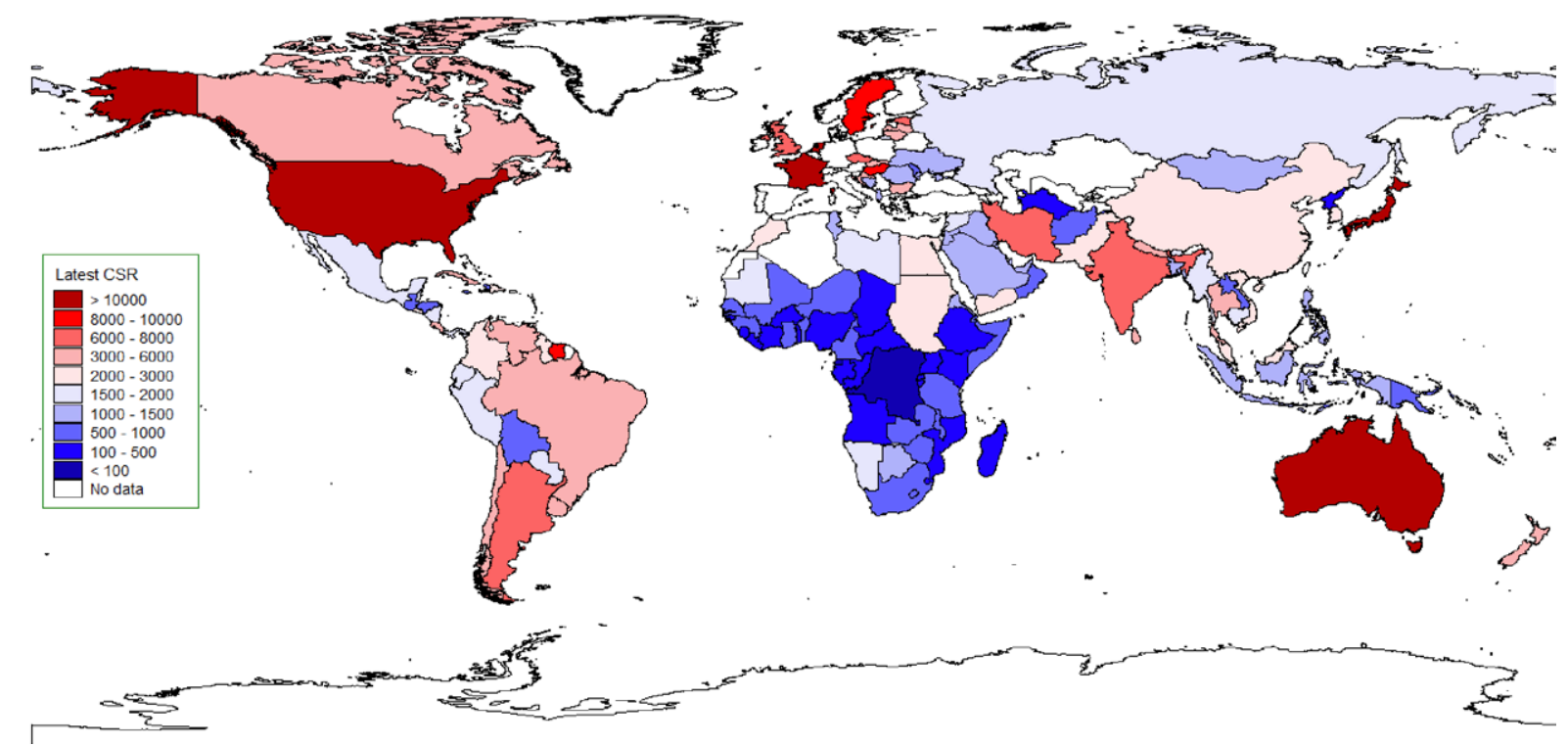


Figure 2: Cross-sectional analysis of association between CSR and socioeconomic development
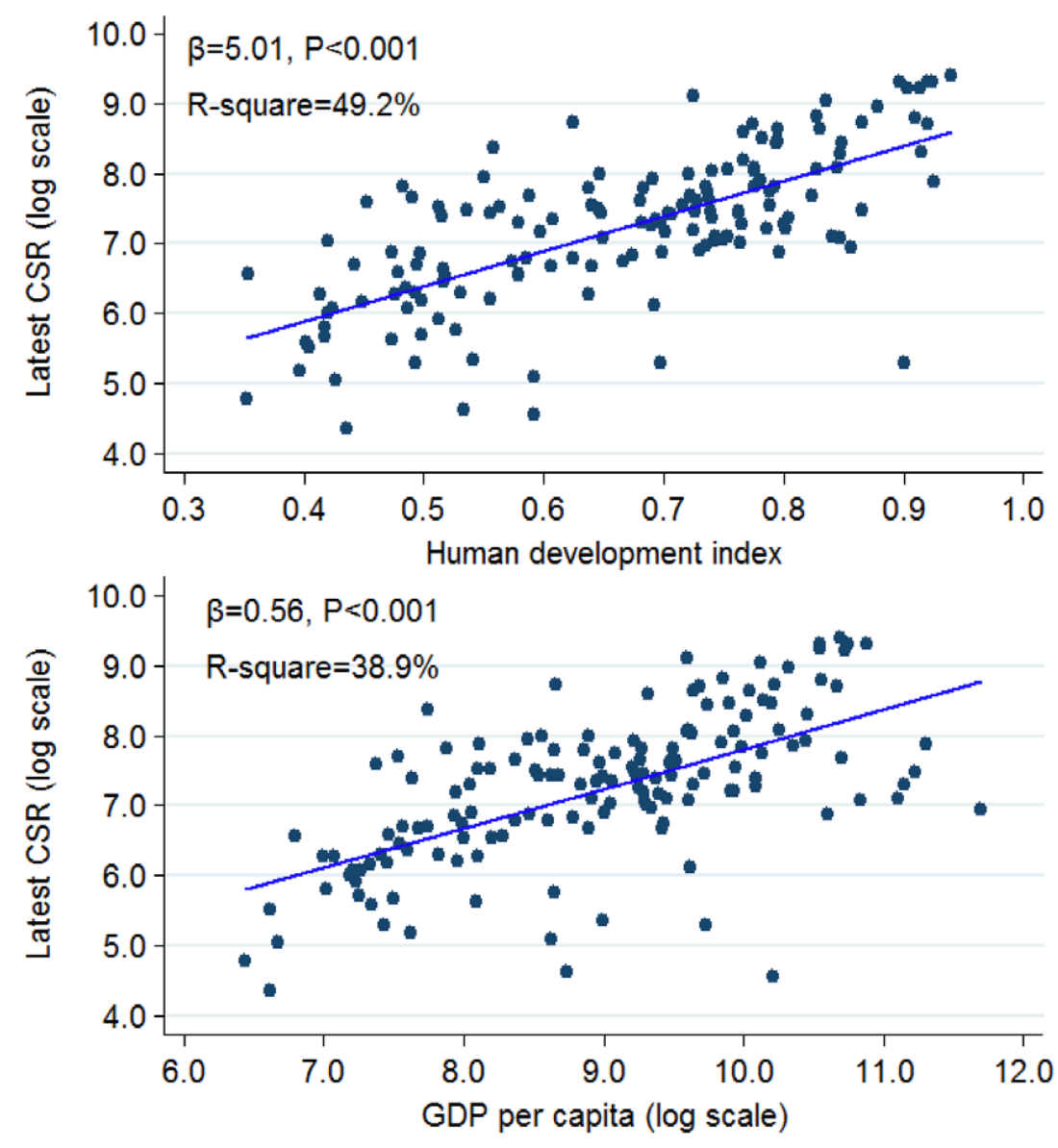

This article is protected by copyright. All rights reserved. 
Figure 3: CSR Changes relative to Australia's CSR from 2006 to 2014

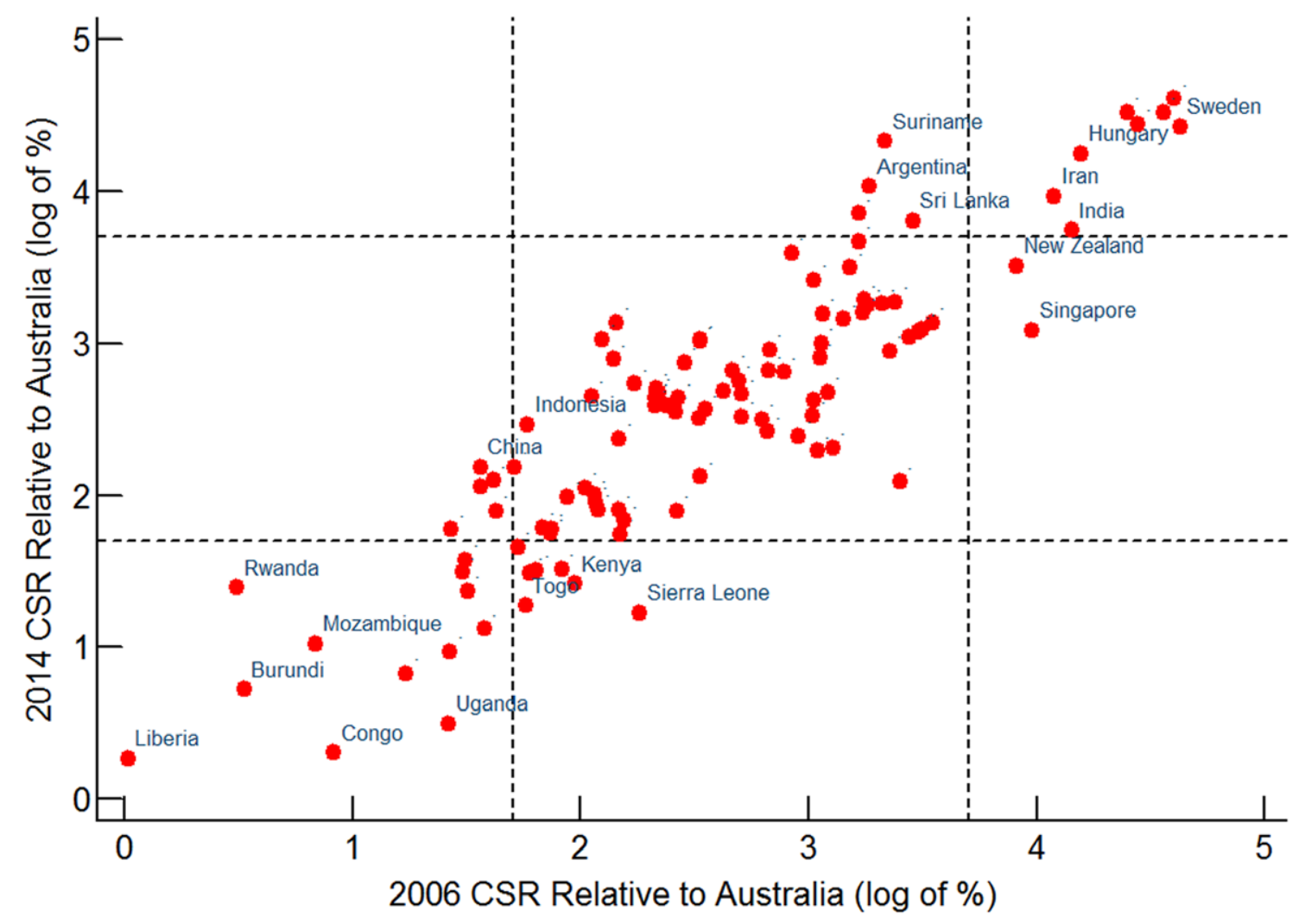

This article is protected by copyright. All rights reserved. 
Figure 4: Time trends of inequality in CSR distribution worldwide

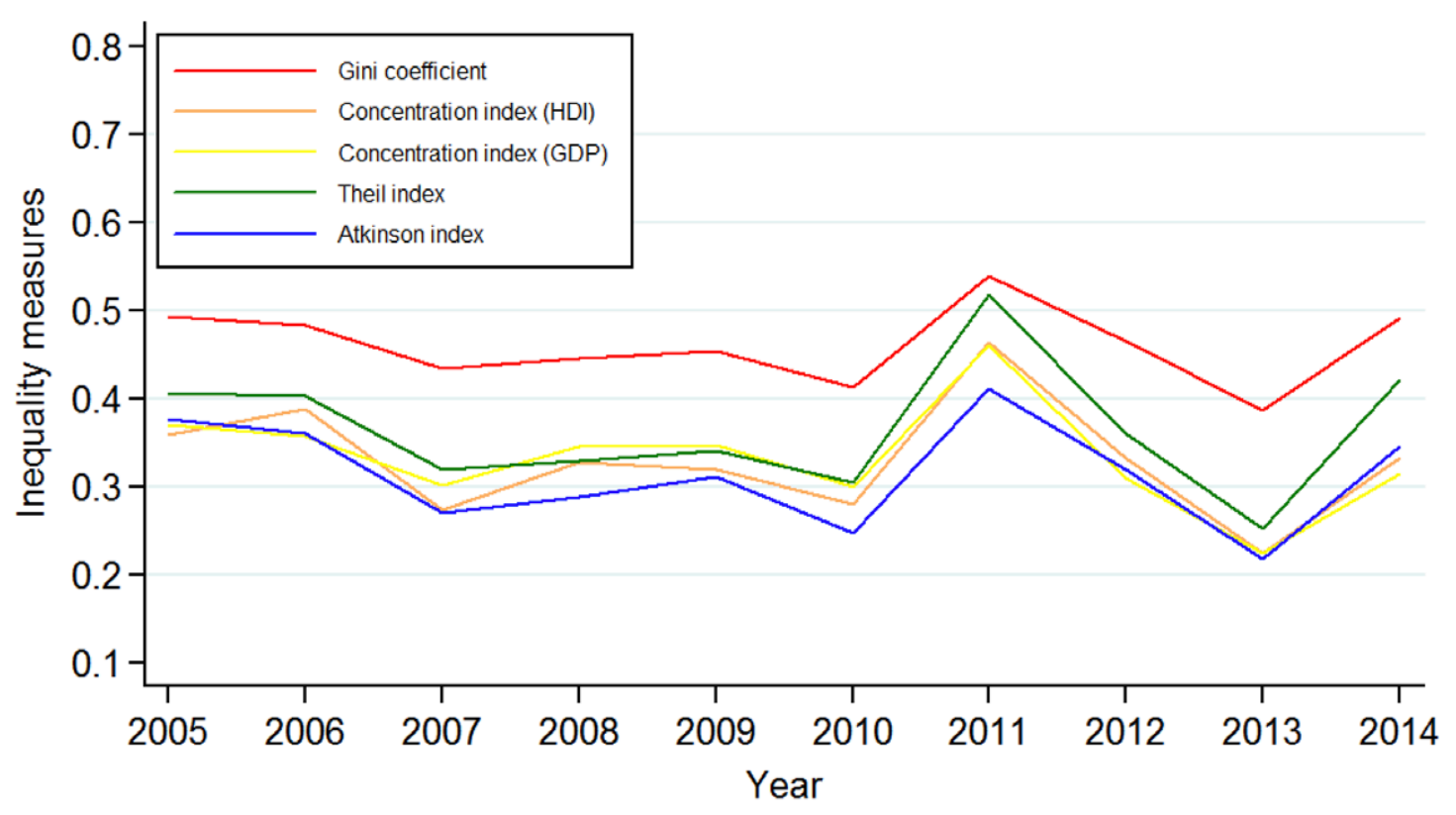

This article is protected by copyright. All rights reserved. 


\section{University Library}

\section{- M M N E R VA A gateway to Melbourne's research publications}

Minerva Access is the Institutional Repository of The University of Melbourne

Author/s:

Yan, W;Wang, W;van Wijngaarden, P;Mueller, A;He, M

Title:

Longitudinal changes in global cataract surgery rate inequality and associations with socioeconomic indices

Date:

2019-05-01

Citation:

Yan, W., Wang, W., van Wijngaarden, P., Mueller, A. \& He, M. (2019). Longitudinal changes in global cataract surgery rate inequality and associations with socioeconomic indices. CLINICAL AND EXPERIMENTAL OPHTHALMOLOGY, 47 (4), pp.453-460. https:// doi.org/10.1111/ceo.13430.

Persistent Link:

http://hdl.handle.net/11343/284685 